\title{
Epidural Catheter Placement for Cerebrospinal Fluid Drainage in Aortic Aneurysm Surgery With Delayed Paraplegia: A Case Report
}

\author{
Cengiz Sahutoglu, ${ }^{\mathrm{a}, \mathrm{b}}$, Zeynep Pestilci ${ }^{\mathrm{a}}$, Seden Kocabas ${ }^{\mathrm{a}}$, \\ Fatma Zekiye Askar ${ }^{\mathrm{a}}$
}

\begin{abstract}
Neurological complications such as paraparesis and paraplegia may occur due to spinal cord ischemia in descending aorta surgery. One of the many methods to decrease these complications is to place cerebrospinal fluid (CSF) drainage catheter. The aim of using this catheter is to decrease CSF pressure and to increase medulla spinalis perfusion pressure. Herein, we report epidural catheter placement for drainage in a case in whom a CSF catheter was unable to be inserted during the pre- and postoperative period due to a descending aortic aneurysm and in whom paraplegia developed.
\end{abstract}

Keywords: Epidural catheter; Paraplegia; Aortic aneurysm; Cerebrospinal fluid

\section{Introduction}

Aneurysm surgeries involving descending aorta are among high-risk operations whose majority of complications occur due to ischemic damage in the organs in distal cross-clamp. These organs include kidneys, the liver, intestines, and spinal cord depending on the location of the cross-clamp. Spinal cord is the most sensitive organ to ischemia and any ischemic damage may result in neurological damages, such as paraparesis and paraplegia [1-5]. Although there has been a significant decrease in mortality and morbidity rates in aortic surgery, paraparesis or paraplegia remains to be problematic after these operations. Depending on the expansion of the aneurysm, preoperative characteristics of the patient, cross-clamping time, and the type of operation, neurological complication rate ranges between $6.5 \%$ and $40 \%[3,4]$.

Manuscript accepted for publication November 24, 2016

aDepartment of Anesthesiology and Reanimation, Ege University Medical Faculty, Izmir, Turkey

${ }^{b}$ Corresponding Author: Cengiz Sahutoglu, Ege Universitesi Tip Fakultesi, Anesteziyoloji ve Reanimasyon AD, 35100, Bornova, Izmir, Turkey. Email: csahutoglu@yahoo.com

doi: https://doi.org/10.14740/jmc2703w
Several methods have been employed to protect from distal organ ischemia until today. However, since a single and reliable method has not been found to avoid complications, several methods are being used in combination. Some of the major ones of these methods are quick surgery, left arteriofemoral bypass during proximal anastomosis, gradual aortic clamping, re-implantation of segmental arteries, and cerebrospinal fluid (CSF) drainage. A CSF catheter is placed in the preoperative period for CSF drainage to decrease the CSF pressure, while increasing medulla spinalis perfusion pressure [1-4]. Herein, we report epidural catheter placement for drainage in a case in whom a CSF catheter was unable to be inserted during the preand postoperative period due to a descending aortic aneurysm and in whom paraplegia developed.

\section{Case Report}

A 50-year-old male patient with a body weight of $90 \mathrm{~kg}$ and a height of $1.70 \mathrm{~cm}$ was scheduled for surgery due to aneurysmatic dilatation originating from the distal left subclavian artery and extending to the infrarenal level, reaching a diameter of $5.9 \mathrm{~cm}$ at the largest in the descending aorta, and 7.8 $\mathrm{cm}$ at the largest in the abdominal aorta. The patient had no other systemic disease, except hypertension in his medical history. His complete blood count, biochemical and coagulation tests were normal. On the day before the operation, CSF drainage catheterization (Medtronic EDM Lumbar Catheter, Goleta, CA, USA) was attempted twice in lumbar 3-4 and 4-5 vertebral spaces; however, it was unable to be placed. A written informed consent was obtained from the patient. He was taken to operation after premedication with morphine $10 \mathrm{mg}$ intramuscular and diazepam $5 \mathrm{mg}$ per oral. Electrocardiography and pulse oximetry were performed, and invasive artery pressure was monitorized. Anesthetic induction was obtained with lidocaine $(1 \mathrm{mg} / \mathrm{kg})$, pentothal sodium $(5 \mathrm{mg} / \mathrm{kg})$, rocuronium bromide $(0.9 \mathrm{mg} / \mathrm{kg})$, and fentanyl $(2 \mu \mathrm{g} / \mathrm{kg})$. After the patient was intubated with a double lumen intubation tube, a $12 \mathrm{~F}$ five lumen catheter through the right vena jugularis interna, rectal heat probe, and transesophageal echocardiography were applied. Anesthesia was maintained with propofol infusion (90 mg/h), sevoflurane (1-1.5 MAC), fentanyl (10 $\mu \mathrm{g} /$ $\mathrm{kg}$ ) and rocuronium bromide, when necessary. The operation was carried out with under hypothermic total circulatory arrest 


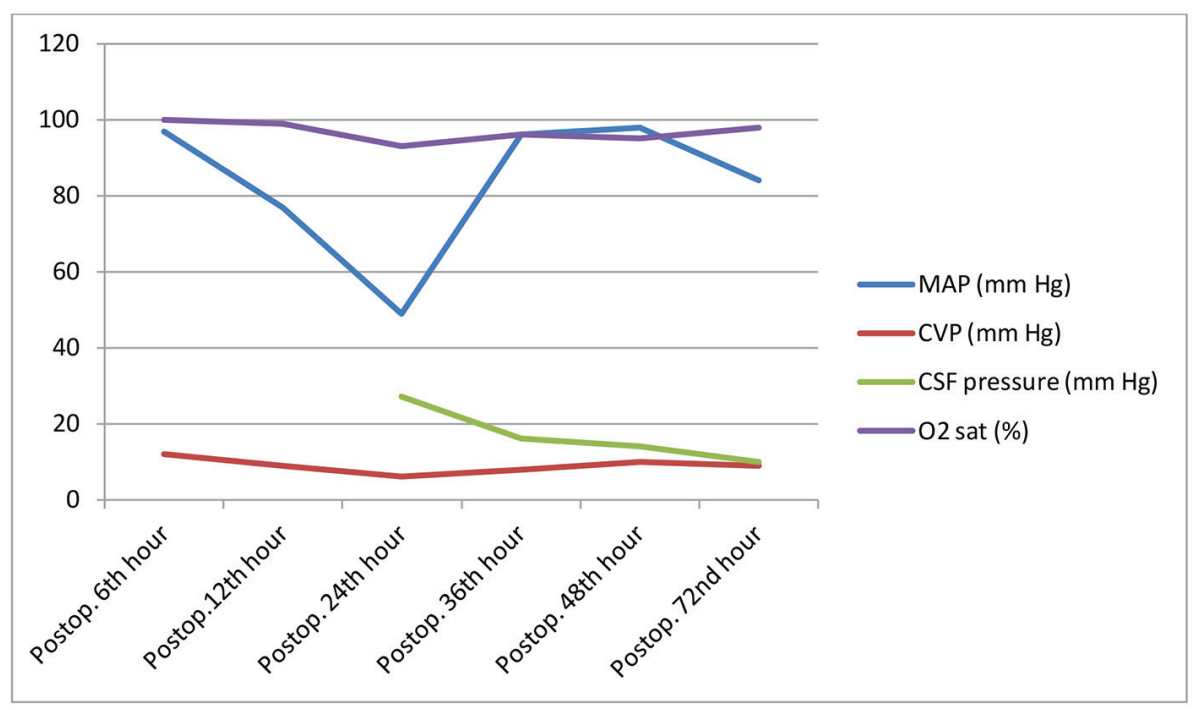

Figure 1. Postoperative hemodynamic values. CSF: cerebrospinal fluid; CVP: central venous pressure; MAP: mean arterial pressure; $\mathrm{O}_{2}$ sat: arterial oxygen saturation; Postop: postoperative.

(TCA) and single lung ventilation with thoracoabdominal incision. Before TCA, the patient was given methylprednisolone $(20 \mathrm{mg} / \mathrm{kg}), 20 \%$ mannitol $(0.5 \mathrm{mg} / \mathrm{kg})$ and was cooled down to $18{ }^{\circ} \mathrm{C}$ (bypass: $191 \mathrm{~min}$, cross-clamping: $55 \mathrm{~min}$, TCA: $27 \mathrm{~min}$, duration of anesthesia: $390 \mathrm{~min})$. Intraoperative four units of erythrocyte suspension (ES), four units of fresh frozen plasma (FFP) and one apheresis platelet were given to patient. The patient was transferred to intensive care unit with the infusion of dopamine $(10 \mu \mathrm{g} / \mathrm{kg} / \mathrm{min})$, adrenaline $(0.2 \mu \mathrm{g} / \mathrm{kg} / \mathrm{min})$, and nitroglycerin $(0.5 \mu \mathrm{g} / \mathrm{kg} / \mathrm{min})$. His blood pressure arterial, heart rate (HR), and central venous pressure (CVP) variables were 120/70 mm Hg, 100/min, and $12 \mathrm{~mm} \mathrm{Hg}$, respectively. He was extubated in the 18th hour of the postoperative period with stable hemodynamics. Neurological examination findings were found to be normal. In the 23rd hour of the postoperative period, shortly after a sudden hypotensive attack (blood pressure arterial: 65/50 mm Hg, HR: 75/min, CVP: $6 \mathrm{~mm} \mathrm{Hg}$, $\mathrm{O}_{2}$ sat: $94 \%$ ), paraplegia occurred (Fig. 1). Considering that the patient's situation was due to spinal hypoperfusion, a CSF catheter was decided to be placed immediately. The patient was put in lateral decubitus position and after lumbal puncture was done from lumbal 4-5 vertebra space, it was seen CSF was coming out. However, the CSF catheter was unable to be proceeded to the subarachnoidal space. It was attempted in the 3-4 lumbar puncture space and was unable to be proceeded again, despite CSF come out (30 min of CSF was drained in these two punctures). Following the second puncture, instead of a CSF catheter, an epidural catheter (Braun Perifix ${ }^{\mathbb{R}}$ One, B. Braun Medical Ltd., Melsungen, Germany) was placed in the subarachnoidal space safely and CSF pressure was observed to increase as much as to reach $27 \mathrm{~mm} \mathrm{Hg}$ in the first measurement. By supporting blood pressure with volume $(500 \mathrm{cc}$ colloid) and inotropes (adrenaline $0.1 \mu \mathrm{g} / \mathrm{kg} / \mathrm{min}$ and dopamine $5 \mu \mathrm{g} / \mathrm{kg} / \mathrm{min}$ ), CSF pressure gradually returned to normal and paraplegia regressed within $6 \mathrm{~h}(3-4 /$ motor power in the lower extremity). Twenty-four hours after paraplegia, neurological examination findings were recorded to be completely normal. The patient whose CSF pressure was observed during $72 \mathrm{~h}$ (emptied with CSF pressure follow-up on day 1: $255 \mathrm{~mL}$, day 2: $15 \mathrm{~mL}$ and day 3: $0 \mathrm{~mL}$ ) was observed for 5 days in the intensive care unit before he was taken to the ward and discharged without any sequelae.

\section{Discussion}

The most worrying complication in thoracic aorta surgery is paraplegia. About $11 \%$ of the patients may have temporary postoperative sequela and $6 \%$ permanent paraplegia. Large surgical dissection, immediate surgery, cross-clamping durations over $30 \mathrm{~min}$, hypotensive attacks and ligation of spinal arteries increase the risk of paraplegia. Applications including temporary heparin covered shunts, hypothermic partial CPB implementation, and re-implantation of spinal arteries are methods to reduce the risk of paraplegia. The arterial blood supply of the medulla spinalis is maintained via vertebral arteries, thoracic and abdominal aorta. In the lower thoracic and abdominal region, anterior spinal arteries (Adamkiewicz artery) branch from the left side of the aorta and are always single. This artery may be damaged during surgical dissections and may be obstructed with a cross-clamp [1-9].

When a cross-clamp is placed on the aorta, the blood pressure increases in the proximal region of the clamp and, as a result, cardiac after load and CSF pressure increase. Increased CSF pressure causes compression on spinal veins and neural texture, reduced spinal cord perfusion pressure, and spinal ischemia. In addition, CSF drainage has been shown to increase spinal cord perfusion pressure and decrease rates of paraplegia in the experiments carried out on animals [6]. Spinal cord perfusion pressure is calculated by subtracting CSF pressure from the mean blood pressure. To increase spinal cord perfusion pressure, the mean blood pressure is attempted to be increased, 
while CSF is decreased. A mean blood pressure of $50 \mathrm{~mm} \mathrm{Hg}$ is the lower limit at which autoregulator systems can sustain normal spinal cord blood flow. This pressure should be kept over $50 \mathrm{~mm} \mathrm{Hg}$. Where it is inconvenient, central vein pressure should be decreased to increase effective perfusion pressure [7].

In our case, the mean arterial pressure was attempted to be increased initially with volume loading and inotrope treatment after the spinal hypotension. Therefore, in addition to a quick load of $500 \mathrm{~mL}$ colloid, doses of dopamine and adrenaline infusions were increased to have a mean artery pressure of $90-100 \mathrm{~mm} \mathrm{Hg}$. Since the attempts to place a spinal catheter failed, an epidural catheter was placed in the subarachnoidal space of the patient in lateral position and by decreasing CSF pressure under $10 \mathrm{~mm} \mathrm{Hg}$, spinal perfusion pressure can be increased and paraplegia cleared up quickly.

Furthermore, proximal hypertension following crossclamping of the thoracic aorta leads to increased volumes and blood accumulation results in increased CSF pressure. Therefore, in the surgical treatment of distal aorta pathologies including high risk today, CSF drainage is suggested as a standard. CSF drainage also allows for avoiding neurotoxic substances and hazardous proteins which develop during cross-clamping $[8,9]$. Paraplegia may develop during the intraoprative period, while several studies have shown paraplegia development in the late postoperative period. The reason for this delayed paraplegia is the spinal cord ischemia caused by hypotension or spinal cord edema [5]. Our case developed paraplegia following sudden hypotension in the postoperative 23rd hour. The fact that the patient was observed in the intensive care unit as invasive monitorized and the operation team was right next to him provided a chance of immediate intervention. In the first two attempts, approximately $30 \mathrm{~mL}$ of CSF was emptied. In the second dural puncture, since the CSF catheter was unable to be proceeded, a more rigid epidural catheter was placed in the subarachonidal area. The failure to place the spinal catheter was associated with the softness of the catheter and the possible adhesions in the spinal space. Spinal perfusion pressure was found to be under the critical value even after emptying $30 \mathrm{~mL}$ of CSF. After the catheter was placed and fixated, the patient's neurological deficit started to improve quickly $(2 / 5$ motor movement in feet). Following a $50 \mathrm{~mL}$ CSF drainage in total, the patient had headaches and nausea-vomiting (TA: 135/85 mm Hg, CSF pressure: $17 \mathrm{~mm} \mathrm{Hg}$, HR: 105/min). As these symptoms were associated with rapid CSF emptying (due to intracranial hypotension), he was given paracetamol $1 \mathrm{~g}$ infusion and ondansetrone $8 \mathrm{mg}$ intravenous. In addition, CSF drainage was recessed, until his complaints decreased. The patient was observed for 3 days; therefore, his CSF drainage was under $10 \mathrm{~mm} \mathrm{Hg}$ and CSF drainage was continued, when necessary (a total of $270 \mathrm{~mL}$ CSF was emptied in three days). In the repeated MRI before discharge, central hyperintense signal alterations (infarct) were detected in the spinal cord between T5-9 and paraplegia attack was verified to be due to the edema following the spinal cord ischemia.

In conclusion, in descending aorta surgery, paraplegia or paraparesis may occur in the postoperative period as well as the intraoperative period. In addition to hemodynamic stabilization to reduce this risk, placement of CSF drainage is a significant choice for treatment. Patients who are scheduled for this type of surgery should be observed closely for paraplegia and paraparesis and be definitely monitorized with CSF pressure. It should not be forgotten that aggressive drainage may cause intracranial hypotension.

\section{Consent}

Written informed consent was obtained from the patient who participated in this case.

\section{Conflicts of Interest}

No conflicts of interest were declared by the authors.

\section{Financial Disclosure}

The authors declared that this study has received no financial support.

\section{Author Note}

This article was presented as a poster statement at the 19th National Congress of Cardiothoracic and Vascular Anesthesia and Intensive Care Association on May 16 - 19, 2013 in Trabzon, Turkey.

\section{References}

1. Svensson LG. An approach to spinal cord protection during descending or thoracoabdominal aortic repairs. Ann Thorac Surg. 1999;67(6):1935-1936; discussion 19531938.

2. Safi HJ, Miller CC, 3rd. Spinal cord protection in descending thoracic and thoracoabdominal aortic repair. Ann Thorac Surg. 1999;67(6):1937-1939; discussion 1953-1938.

3. Livesay JJ, Cooley DA, Ventemiglia RA, et al. Surgical experience in descending thoracic aneurysmectomy with and without adjuncts to avoid ischemia. Ann Thorac Surgery. 1985;39:37-46.

4. Crawford ES, Crawford JL, Safi HJ, Coselli JS, Hess KR, Brooks B, Norton HJ, et al. Thoracoabdominal aortic aneurysms: preoperative and intraoperative factors determining immediate and long-term results of operations in 605 patients. J Vasc Surg. 1986;3(3):389-404.

5. Attaran S, Desmond M, Field M, Oo A. Successful reversal of delayed paraplegia associated with chronic type A aortic dissection using a spinal drain. Interact Cardiovasc Thorac Surg. 2010;11(3):374-375.

6. Mauney MC, Blackbourne LH, Langenburg SE, Buchanan SA, Kron IL, Tribble CG. Prevention of spinal cord injury after repair of the thoracic or thoracoabdominal aorta. Ann Thorac Surg. 1995;59(1):245-252. 
7. Fedorow CA, Moon MC, Mutch WA, Grocott HP. Lumbar cerebrospinal fluid drainage for thoracoabdominal aortic surgery: rationale and practical considerations for management. Anesth Analg. 2010;111(1):46-58.

8. Svensson LG, Hess KR, D'Agostino RS, Entrup MH, Hreib K, Kimmel WA, Nadolny E, et al. Reduction of neurologic injury after high-risk thoracoabdominal aortic operation. Ann Thorac Surg. 1998;66(1):132-138.

9. Safi HJ, Winnerkvist A, Miller CC, 3rd, Iliopoulos DC, Reardon MJ, Espada R, Baldwin JC. Effect of extended cross-clamp time during thoracoabdominal aortic aneurysm repair. Ann Thorac Surg. 1998;66(4):1204-1209. 